\title{
Awareness of Oral Hygiene and Esthetic Vigilance among Youngsters: A Web-based Study
}

\author{
Sai Priya Jilkapally ${ }^{1}$, Jammula Surya Prasanna²
}

\begin{abstract}
Aim and objective: To assess awareness and vigilance of oral health and esthetics among the young population.

Materials and methods: A web-based, self-constructed, multiple-choice questionnaire consisting of 19 questions prepared on Google forms application was used for the survey and distributed using Gmail, WhatsApp among 246 youngsters with an age group ranging from 15 to 30 years selected adopting a convenient sampling method.

Results: The result of the study shows awareness of oral hygiene and esthetics were moderate among the youngsters. Ninety-eight percent think oral cleanliness is required and $58.9 \%$ brush only once daily. $73.6 \%$ brush only to maintain cleanliness. $90.7 \%$ were concerned about the esthetics and $81.7 \%$ would like to resolve the problem to enhance esthetics and $35.2 \%$ found the treatment expensive. Only $50 \%$ of them were aware of a specialist called a periodontist and $54 \%$ visit a general dentist and $31.7 \%$ like to visit a dentist only in times of any oral problem.

Conclusion: The majority of the subjects were unaware of a specialist named a periodontist and would visit a general dentist in times of need. Thus, there is a definite need to focus on spreading awareness among youngsters regarding oral hygiene maintenance and esthetic corrections in compromised conditions.
\end{abstract}

Keywords: Brushing, Esthetics, Oral hygiene, Youngsters.

CODS Journal of Dentistry (2020): 10.5005/jp-journals-10063-0061

\section{INTRODUCTION}

In modern society, a pleasing esthetic appearance has become a high priority along with oral health. The facial profile and the oral structural alignment are one of the first features people look at; a pleasant smile is a key factor for attraction. But people's perception of oral health and esthetics has been seen to vary from one individual to another as every other individual has a different point of view with the prospects of health and appearance. Some people comply better with oral health care regimens and some with esthetics. Lack of awareness of dental procedures are reasons for non-adherence to oral care practices among youngsters. ${ }^{1}$ Hence, proper oral care knowledge is a must to avoid oral complaints in the future. A webbased study has its advantages of easy data collection, recording, and maintenance of data for statistical analysis, being cost-effective and in less time. So, the present study was conducted to assess the oral hygiene and esthetic awareness among youngsters and to increase knowledge on dental procedures.

\section{Materials and Methods}

\section{Sample Size and Sampling Procedure}

A web-based, self-constructed, multiple-choice questionnaire consisting of 19 questions along with one pictorial question was prepared on the Google forms app and was circulated among 246 youngsters from urban and rural areas of all over India selected by adopting convenient sampling method of both genders with an age group ranging from 15 to 30 years. The questionnaire was prepared in English and was distributed through Gmail, WhatsApp among youngsters pursuing education and working in their respective professions other than a dental specialty.

The elicited information was on sociodemographic characteristics, oral hygiene and esthetic knowledge, and knowledge about dental specialties. The reason for undertaking

\footnotetext{
1,2Department of Periodontics, Panineeya Institute of Dental Sciences, Hyderabad, Telangana, India
}

Corresponding Author: Sai Priya Jilkapally, Department of Periodontics, Panineeya Institute of Dental Sciences, Hyderabad, Telangana, India, Phone: +919948128554, e-mail: jpriyajess@gmail. com

How to cite this article: Jilkapally SP, Prasanna JS. Awareness of Oral Hygiene and Esthetic Vigilance among Youngsters: A Web-based Study. CODS J Dent 2020;12(2):35-40.

Source of support: Nil

Conflict of interest: None

young individuals is their vast exposure to social media and interest in one's appearance and also to increase the awareness of different esthetic dental procedures and improve oral health status.

\section{Results}

\section{Sociodemographic Characteristics of Study Participants}

Among the 246 participants, 134 (54.4\%) were female and 112 $(45.5 \%)$ were male (Table 1$)$.

Table 1: Sociodemographic characteristics of study participants $(n=246)$

\begin{tabular}{llc}
\hline Variable & Number & Frequency (\%) \\
\hline Age & $15-20$ & $19(7.7)$ \\
& $21-25$ & $139(56.5)$ \\
& $26-30$ & $88(35.7)$ \\
Sex & Female & $134(54.4)$ \\
& Male & $112(45.5)$ \\
\hline
\end{tabular}




\section{Responses and Awareness of Oral Cleanliness}

Two hundred and forty-one (98\%) thought oral cleanliness is required and 145 (58.9\%) of them brush only once a day (Fig. 1). One hundred and fifty (61\%) take only 1-5 minutes to brush (Fig. 2). One hundred and ninety-eight (80.8\%) thought that the time taken for cleaning/brushing matters to maintain oral health (Fig. 3). Two hundred and eleven (85.8\%) thought cleaning the tongue helps in oral health maintenance. One hundred and ninety-one (77.6\%) said they clean the tongue every day after brushing. One hundred and eighty-one (73.6\%) brush every day to maintain cleanliness, whereas 32 (13\%) considered it a daily routine habit (Fig. 4). One hundred and seventy (69.1\%) knew about rinsing the mouth every time after brushing but only 72 (29.3\%) used mouthwash, whereas 174 (70.7\%) did not use mouthwash after brushing. One hundred and forty-two (57.7\%) rinse the mouth after intake of any type of meal (Table 2).

\section{The Response of Participants on Esthetic Awareness and Dental Treatment Considerations}

Two hundred and twenty-three (90.7\%) were concerned about the esthetics and 59 (24\%) and 54 (22\%) thought correcting irregularly arranged teeth and black gums, respectively, can enhance esthetics

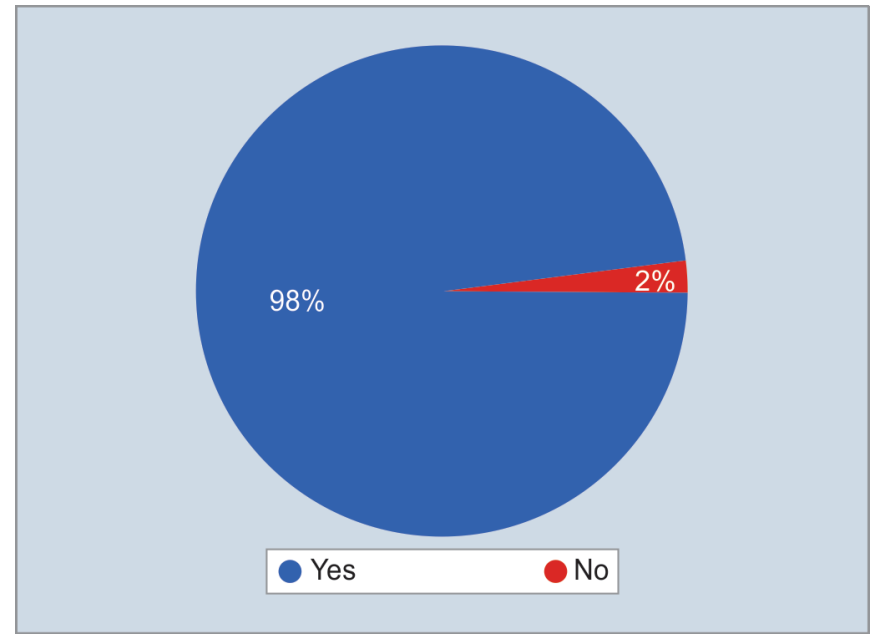

Fig. 1: Percentage of study participants thinking oral cleanliness is required

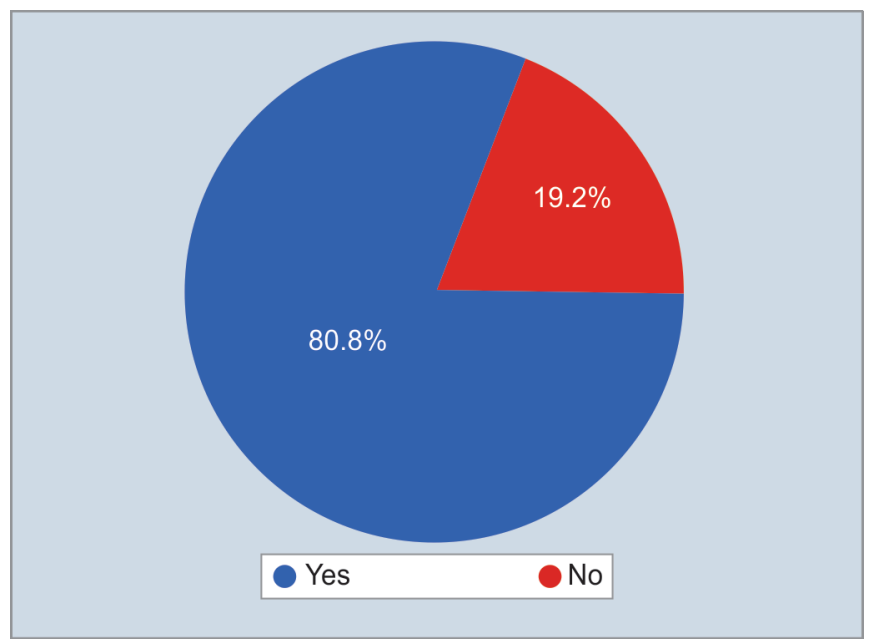

Fig. 3: Percentage of participants thinking the time taken for brushing matters to maintain oral health $(n=246)$
(Figs 5 and 6). One hundred and eighty-six (75.6\%) knew that the mentioned dental problems can be corrected, 201 (81.7\%) would like to correct the problem to enhance esthetics, and 88 (35.2\%) found the treatment expensive. Only 123 (50\%) of them were aware of a specialist called a periodontist and 128 (54\%) visit a general dentist and 78 (31.7\%) visit a dentist only in times of dental problem (Fig. 7 and Table 3).

\section{Discussion}

"Oral Health for a Healthy Life" was the theme declared by the World Health Organization (WHO) on World Health Day 1994. ${ }^{2}$ Complete oral health with disease-free teeth and supporting tissues are considered important. A healthy set of teeth and gingiva also form an important part of what is now known as facial esthetics.

It is a known fact in India that oral hygiene is considered less important and has mostly remained ignored, unimportant, and unrealized. Most of the systemic diseases show their first signs and symptoms through the oral cavity and they remain undiagnosed or untreated because of this missing awareness.

Gingival esthetics is an important component of an attractive smile. Esthetic restorations surrounded by unesthetic gingival tissue can harm a smile and one's confidence. Gingival tissues are

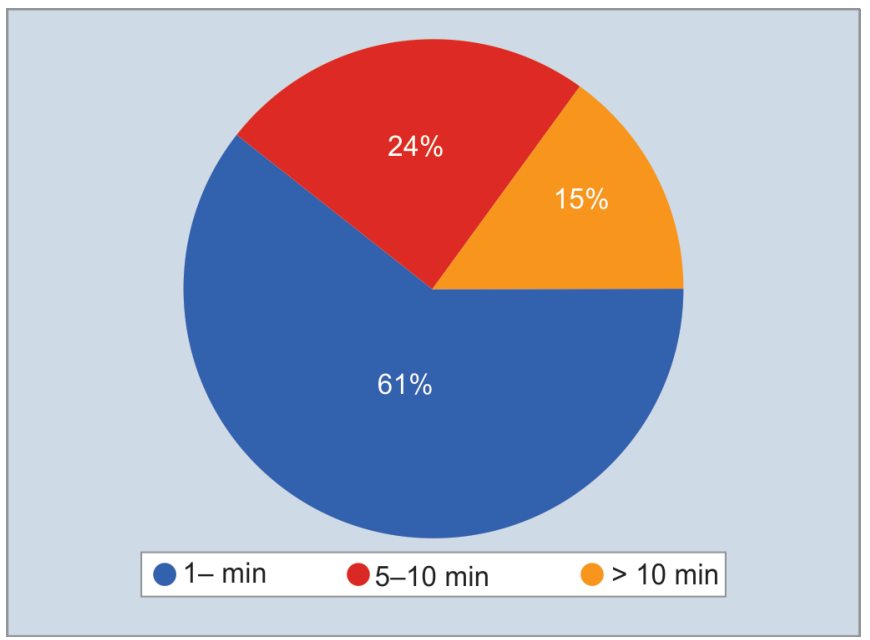

Fig. 2: Participants on time required to clean their oral cavity $(n=246)$

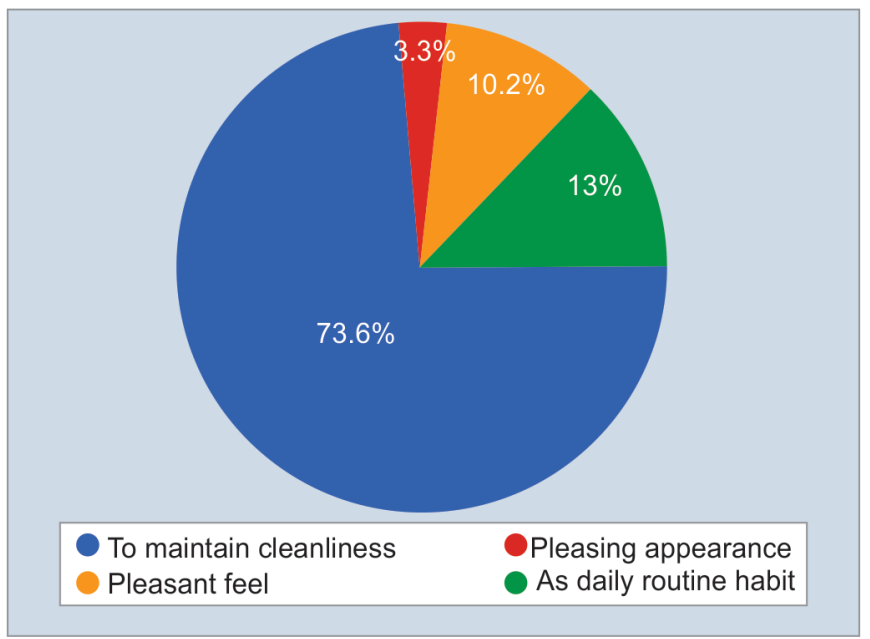

Fig. 4: Percentage of participants thinking the reason to brush $(n=246)$ 
Table 2: Participants response and awareness of oral cleanliness

\begin{tabular}{|c|c|c|}
\hline Question & Category & Frequency (\%) \\
\hline \multirow[t]{2}{*}{ Do you think oral cleanliness is required? } & Yes & $241(98)$ \\
\hline & No & $5(2)$ \\
\hline \multirow[t]{3}{*}{ How often do you clean your oral cavity? } & Once-daily & $145(58.9)$ \\
\hline & Twice daily & $68(27.6)$ \\
\hline & Whenever you feel like you want to & $33(13.4)$ \\
\hline \multirow[t]{3}{*}{ How much time do you take to clean your teeth? } & $1-5$ minutes & $150(61)$ \\
\hline & $5-10$ minutes & $59(24)$ \\
\hline & $>10$ minutes & $37(15)$ \\
\hline \multirow[t]{2}{*}{ Do you think the time you take for brushing matters to maintain oral health? } & Yes & $198(80.8)$ \\
\hline & No & $47(19.2)$ \\
\hline \multirow[t]{2}{*}{ Do you think cleaning the tongue helps in oral health maintenance? } & Yes & $211(85.8)$ \\
\hline & No & $35(14.2)$ \\
\hline \multirow[t]{2}{*}{ Do you clean your tongue every day after brushing? } & Yes & $191(77.6)$ \\
\hline & No & $55(22.4)$ \\
\hline \multirow[t]{4}{*}{ Why should we brush? } & To maintain cleanliness & $181(73.6)$ \\
\hline & Pleasing appearance & $8(3.3)$ \\
\hline & Pleasant feel & $25(10.2)$ \\
\hline & As a daily routine habit & $32(13)$ \\
\hline \multirow[t]{2}{*}{ Do you know anything about rinsing your mouth? } & Yes & $170(69.1)$ \\
\hline & No & $76(30.9)$ \\
\hline \multirow[t]{2}{*}{ Do you use mouthwash after brushing? } & Yes & $72(29.3)$ \\
\hline & No & $174(70.7)$ \\
\hline \multirow[t]{2}{*}{ Do you rinse your mouth after intake of any type of food? } & Yes & $142(57.7)$ \\
\hline & No & $104(42.3)$ \\
\hline \multirow[t]{4}{*}{ What is your priority of interest in cleaning? } & Teeth & $74(30.1)$ \\
\hline & Gums & $3(1.2)$ \\
\hline & Tongue & $5(2)$ \\
\hline & All the above & $164(66.7)$ \\
\hline
\end{tabular}

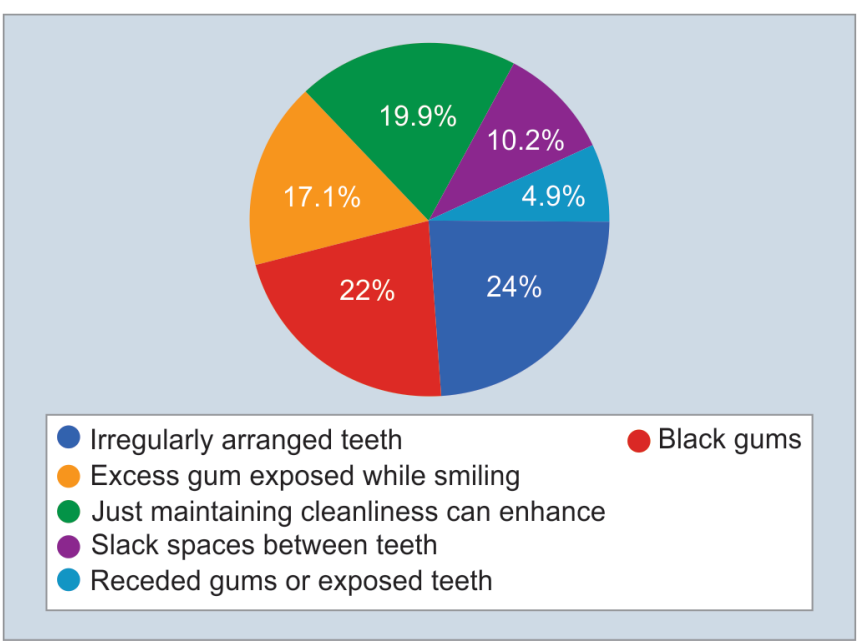

Fig. 5: Respondent's reason to enhance the appearance $(n=246)$

the most pleasing with little exposure to keratinized and mucosal tissue. The excessively exposed gingiva can distract from the overall appearance, regardless of the good appearance of other elements. Youngsters who are considered as the future of India are studied to help them in attaining oral hygiene and care about esthetics by creating awareness but their busy lifestyle and frequent migrations for study or professional purposes would be a limitation for them to attain the same.

Circulating through Gmail and WhatsApp is handy to all as smartphones are ruling the world and available to everyone, this approach can reach a wide number of people. A limitation of this approach is the easy forwarding nature of people which makes the questionnaire accessible to any individual and replies from the unwanted members of the study.

The commonly reported frequency for oral hygiene practices is $1-2$ times a day. In this study, only $27.6 \%$ reported to brush twice daily which is in accordance with the study done by Kapoor et al., and Jain et al., who reported low proportions of 25 and $23 \%$ of their studied population, ${ }^{1,3}$ contradicting to this were the studies were done by Dilip among Police recruits, ${ }^{4}$ Jiang et al. among the Chinese urban adolescents ${ }^{5}$, Al-Shammari et al. among the Kuwaiti adults, ${ }^{6}$ and Zhu et al. among the middle-aged and the elderly Chinese adults in urban areas $^{7}$ who reported $58,67,62,50$, and $75 \%$ proportions, respectively.

The present study showed that $77.6 \%$ of the studied population clean their tongue. $57.7 \%$ rinse the mouth after intake of any type of meal, only $29.3 \%$ of the subjects use mouthwash. Whereas in a study by Kapse et al., ${ }^{8} 84 \%$ of individuals had developed the proper habit of cleaning the tongue and $71 \%$ rinse their mouth after the 

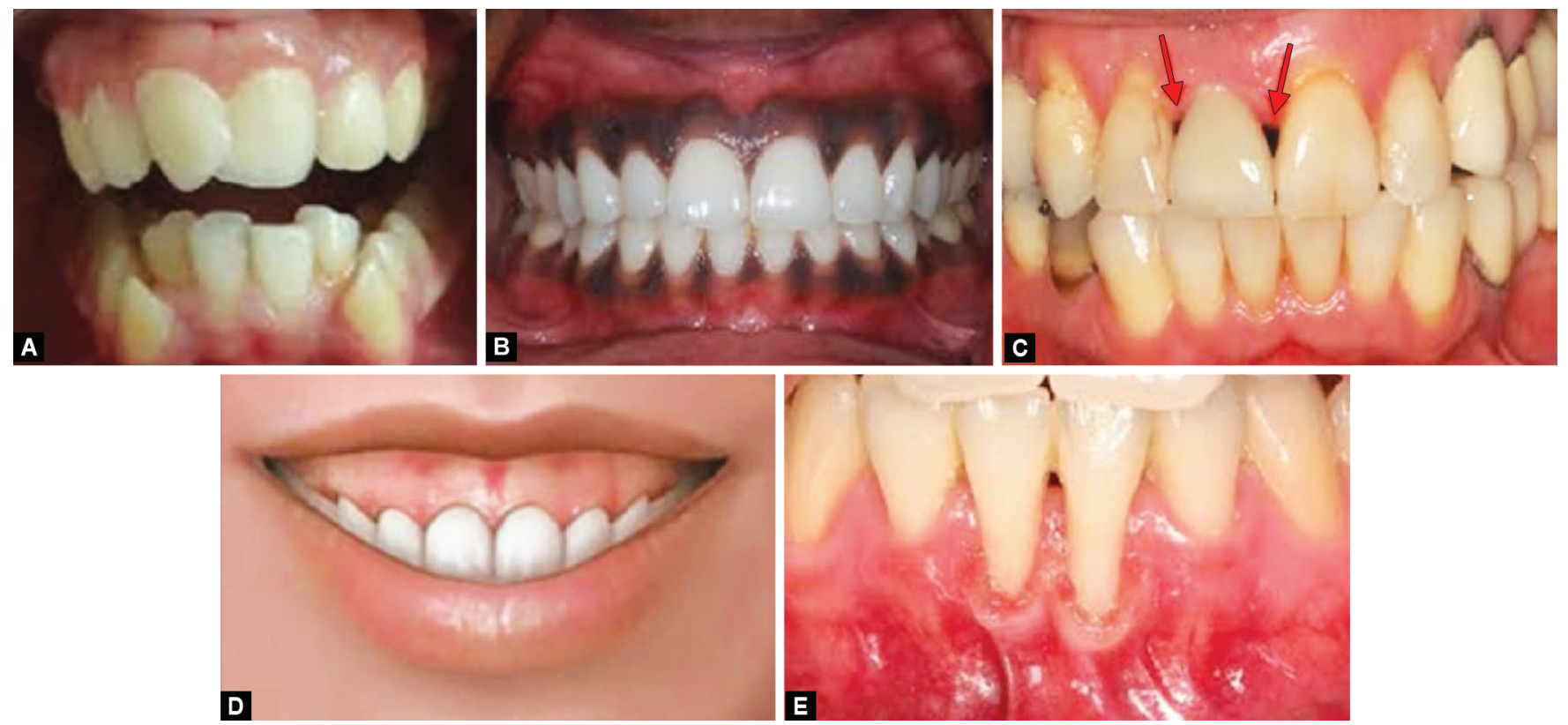

Figs $6 \mathrm{~A}$ to E: Which among the following corrected, can enhance the appearance (Pictorial question): (A) Irregularly arranged teeth; (B) Black gums; (C) Excess gum exposed while smiling; (D) Black space between teeth; (E) Receded gums or exposed teeth

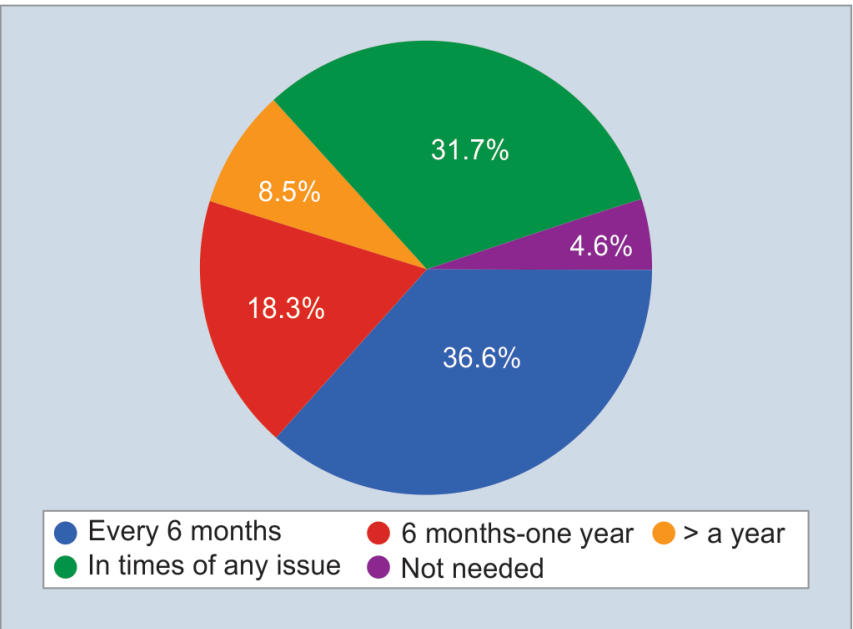

Fig. 7: Percentage of participant's reasons to visit the dentist $(n=246)$

meal in their daily routine, $25 \%$ of participants use mouthwash, and $67 \%$ did not use mouthwash even $7 \%$ individuals not even known about mouthwash. This shows a lack of awareness.

Our study showed that $31.7 \%$ of the subjects visit a dentist in times of need, among other studies Al-Beiruti, ${ }^{9}$ in 1997 , reported $69.5 \%$ of the participants to visit a dentist only when they have pain. In a study done by Ganesh et al. ${ }^{10}$ on oral health awareness and oral hygiene status of 12 - and 15 -year-old children in Chennai $40.7 \%$ of the children had never visited a dentist. Varenne et al. ${ }^{11}$ in 2006 in Africa in their study, $93 \%$ of the children and $90 \%$ of the children in a study by Leung and Chu in China, ${ }^{12}$ had never visited a dentist.

As the participants can be non-dental professionals, a pictorial question was included that gave them a clear vision of the problems, pictures that included were irregularly arranged teeth, black gums, excess gum exposed while smiling, black spaces between teeth, receded or exposed gums (Figs 5 and 6).
Only $90.7 \%$ were concerned about esthetics in the present study and $24 \%$ thought correcting irregularly arranged teeth can enhance esthetics which is in accordance with the study done by Faizee et al., ${ }^{13}$ reported that $>70 \%$ of the participants showed their interest in self-image, $39.9 \%$ of the total study population was unhappy with the arrangement of their teeth.

The level of marginal gingiva of the maxillary anterior teeth also influences the esthetic appearance of a smile, which should be located along a horizontal line extending from cuspid to cuspid. In the current study, $17.1 \%$ thought that correcting the excess gum exposed can improve esthetics. In the study done by Shetty et al., there was no awareness of the gingival recession. ${ }^{14}$

The survey of adults showed that those who had check-ups had almost half as many teeth missing as those who visited the dentist only in times of problem. ${ }^{15}$ In the present study, $31.7 \%$ visit dentist only in times of dental problem.

\section{Limitations}

The study could be more effective if done offline.

\section{CONCLUSION}

Awareness of oral hygiene and esthetics was moderate among youngsters. Esthetic concern was significant among most of them. A significant number of participants knew oral problems can be corrected but were hesitant to correct them concerning the expenses of the treatment. Most of them were unaware of a specialist named a periodontist and would visit a general dentist in times of need. Thus, there is a definite need to focus on spreading awareness among youngsters regarding oral hygiene maintenance and esthetic corrections in compromised conditions. We, as dentists, will have to keep reinforcing the importance of oral hygiene and esthetics awareness among the youngsters. This study helps in enhancing the knowledge and attitude of the young population on oral hygiene and esthetics. 
Table 3: Response of participants on esthetic awareness and dental treatment considerations $(n=246)$

\begin{tabular}{|c|c|c|}
\hline Question & Category & Frequency (\%) \\
\hline \multirow[t]{2}{*}{ Does appearance matter to you? } & Yes & $223(90.7)$ \\
\hline & No & $23(9.3)$ \\
\hline \multirow[t]{6}{*}{$\begin{array}{l}\text { What among the following corrected, can enhance the appearance in your opinion? (Pictorial } \\
\text { question, Fig. 5) }\end{array}$} & $\begin{array}{l}\text { Irregularly arranged } \\
\text { teeth }\end{array}$ & $59(24)$ \\
\hline & Black gums & $54(22)$ \\
\hline & $\begin{array}{l}\text { Excess gum exposed while } \\
\text { smiling }\end{array}$ & $42(17.1)$ \\
\hline & $\begin{array}{l}\text { Just maintaining cleanli- } \\
\text { ness can enhance }\end{array}$ & 49 (19.9) \\
\hline & $\begin{array}{l}\text { Black spaces between } \\
\text { teeth }\end{array}$ & $25(10.2)$ \\
\hline & Receded or exposed gums & $17(6.9)$ \\
\hline \multirow[t]{2}{*}{ Are you aware that the above-mentioned dental problems can be corrected? } & Yes & $186(75.6)$ \\
\hline & No & $60(24.4)$ \\
\hline \multirow[t]{2}{*}{ If you find any of the above-mentioned problems, would you like to correct them? } & Yes & $201(81.7)$ \\
\hline & No & $45(8.3)$ \\
\hline \multirow[t]{3}{*}{ If yes, why? } & $\begin{array}{l}\text { Helps in better social } \\
\text { interaction }\end{array}$ & $73(29.8)$ \\
\hline & $\begin{array}{l}\text { To enhance the esthetic } \\
\text { appearance }\end{array}$ & $116(46.9)$ \\
\hline & Other reason & $57(23.3)$ \\
\hline \multirow[t]{4}{*}{ If no, why? } & Fear of treatment & $57(23.3)$ \\
\hline & $\begin{array}{l}\text { Wants to retain a natural } \\
\text { appearance }\end{array}$ & $36(14.8)$ \\
\hline & Expensive & $88(35.2)$ \\
\hline & Other reason & $65(26.6)$ \\
\hline \multirow[t]{5}{*}{ How frequently one should visit a dentist? } & Every 6 months & $90(36.6)$ \\
\hline & 6 months-a year & $45(18.3)$ \\
\hline & $>$ a year & $21(8.5)$ \\
\hline & In times of any issue & $78(31.7)$ \\
\hline & Not needed & $12(4.9)$ \\
\hline \multirow[t]{3}{*}{ In times of any oral problem, you visit } & $\begin{array}{l}\text { A specialist concerned } \\
\text { with the issue }\end{array}$ & $87(35.4)$ \\
\hline & A general dentist & $134(54.5)$ \\
\hline & Any medical practitioner & $25(10.2)$ \\
\hline \multirow[t]{2}{*}{ Are you aware of a specialty called periodontics in dentistry? } & Yes & $123(50)$ \\
\hline & No & $123(50)$ \\
\hline \multirow[t]{2}{*}{ Are you aware that a periodontist deals with all the gum-related problems? } & Yes & $128(52)$ \\
\hline & No & $118(48)$ \\
\hline
\end{tabular}

\section{Acknowledgments}

The authors acknowledge the support from the volunteers who contributed to the study.

\section{References}

1. Kapoor D, Gill S, Singh A, et al. Oral hygiene awareness and practice amongst patients visiting the department of periodontology at a dental college and hospital in north India. Indian J Dent 2014;5(2):6468. DOI: 10.4103/0975-962X.135262.

2. World Health Association. Previous World Health Days. Geneva: World Health Association; 2016. Available from: http://www.who. int/world-health-ay/previous/en/.

3. Jain N, Mitra D, Ashok KP, et al. Oral hygiene-awareness and practice among patients attending OPD at Vyas Dental College and
Hospital, Jodhpur. J Indian Soc Periodontol 2012;16(4):524-528. DOI: 10.4103/0972-124X.106894.

4. Dilip CL. Health status, treatment requirements, knowledge, and attitude towards oral health of police recruits in Karnataka. J Indian Assoc Public Health Dent 2005;5:20-34.

5. Jiang $H$, Petersen $P E$, Peng $B$, et al. Self-assessed dental health, oral health practices, and general health behaviors in Chinese urban adolescents. Acta Odontol Scand 2005;63(6):343-352. DOI: 10.1080/00016350500216982.

6. Al-Shammari KF, Al-Ansari JM, Al-Khabbaz AK, et al. Selfreported oral hygiene habits and oral health problems of Kuwaiti adults. Med Princ Pract 2007;16(1):15-21. DOI: 10.1159/0000 96134.

7. Zhu L, Petersen PE, Wang HY, et al. Oral health knowledge, attitudes, and behavior of adults in China. Int Dent J 2005;55(4):231-241. DOI: 10.1111/j.1875-595X.2005.tb00321.x. 
8. Kapse P, Yeltiwar RR, Patil P, et al. An online survey about awareness and motivation regarding periodontal health in Maharashtra. Indian Journal of Multidisciplinary Dentistry 2018;8(2): 71-75.

9. Al-Beiruti N. Oral health behavior among a sample of schoolteachers, physicians, and nurses in the Syrian Arab Republic. East Mediterr Health J 1997;3:258-262.

10. Ganesh A, Chaly PE, Reddy VC, et al. Oral health awareness and oral hygiene status of 12- and 15-year-old children in Chennai. J Indian Assoc Public Health Dent 2019;17(3):206-212. DOI: 10.4103/jiaphd. jiaphd_214_18.

11. Varenne B, Petersen PE, Ouattara S. Oral health behaviour of children and adults in urban and rural areas of Burkina Faso.
Africa Int Dent J 2006;56(2):61-70. DOI: 10.1111/j.1875-595X.2006 tb00075.x.

12. Leung WK, Chu CH. Dental caries and periodontal status of 12 -year-old school children in rural Qinghai, China. Int Dent J 2003;53(2):73-78. DOI: 10.1111/j.1875-595X.2003.tb00662.x.

13. Faizee SH, Veerasankar S, Avanthika K, et al. Awareness survey about the effects of malocclusion among young adults. Indian J Dent Res 2018;29(6):705-710. DOI: 10.4103/ijdr.IJDR_748_17.

14. Shetty A, Bhandary R, Thomas B. Awareness on gingival recession and its association to risk factors: an epidemiological study. Research 2014;1:1268. DOI: 10.13070/rs.en.1.1268.

15. Todd JE, Lader D. Adult Dental Health 1988 the United Kingdom. London: Her Majesty's Stationery Office (HMSO); 1991. 